\title{
WHY PAY TAXES WHEN NO ONE ELSE DOES?
}

\author{
Gil S. Epstein* \\ (Bar Ilan University, Ramat Gan and IZA, Bonn and CReAM, London) \\ epsteig@mail.biu.ac.il \\ Ira N. Gang \\ (Department of Economics, Rutgers University and IZA, Bonn and CReAM, London) \\ gang@economics.rutgers.edu
}

March 2009

\begin{abstract}
Abstract

In this paper we try to understand the phenomena whereby a large proportion of the population evades tax payments. We present a model which incorporates elements from the theory of information cascades with the standard model of tax evasion and analyze the connection between the decision of a potential tax evader, the number of tax evaders and the number caught in previous periods. General conditions exist under which any expected utility maximizing potential tax evaders will decide to emulate other tax evaders.
\end{abstract}

Keywords: Tax evasion, Uncertainty, Information cascades.

JEL Classifications: H26, H31, D82.

Correspondence: Ira Gang, Economics Department, Rutgers University, 75 Hamilton St, New Brunswick NJ 08901-1248 USA. email: gang@economics.rutgers.edu Tel : +1 732-932-7363. Fax : +1 732-932-7416.

*Financial support from the Adar Foundation of the Economics Department of Bar-Ilan University is gratefully acknowledged by Gil S. Epstein. 


\section{Introduction}

Taxes are inevitable in life, though many people prefer not paying them. People weigh the costs against the benefits when determining whether, and how much, to tax evade. Since the early work by Allingham and Sandmo (1972) a substantial literature has developed on the economics of tax evasion (Andreoni, Erard and Feinstein, 1998; Goswami, Sanyal, and Gang, 1991; Sanyal, Gang, and Goswami 2000; Das-Gupta and Gang, 2000). The evasion decision in the standard model is captured in a simple expected utility maximizing problem. Based on the probability of detection by the authorities, individuals decide whether to evade and, if they evade, the optimal level of evasion. Empirical evidence reveals inter-dependency among taxpayers, as reflected in the increased likelihood of evasion when others are believed to be evading (Geeroms and Wilmots, 1985). Dunn (1992) has pointed out that strong empirical evidence reveals, contrary to standard tax evasion theory, that deterrence does not increase tax compliance.

Our model looks at the connection between the decision an individual makes regarding tax evasion and the number of other individuals already evading. Awareness is restricted to a single tax: an income tax levied on individuals (households or firm). Awareness of other individuals has begun to be incorporated into evasion models. Gang and Das-Gupta (2003) examine transactions matching, an enforcement activity which systematically throw up information of use in examining other taxpayers. Bose and Gangopadhyay (forthcoming) introduce a role for intermediaries; Hunt (2004) examines the implications of trust and personal relations. Our theoretical framework uses information cascades (herd effects) to explain tax evasion. Information cascades were used by Scharfstein and Stein (1990), Banerjee (1992), Gul and Russell (1995) in investment applications, and by Epstein (2002) to migration. The theory also offers interesting insights in explaining tax evasion.

Potential tax evaders do not have perfect information regarding the best choices or the probability of being caught. Evasion decisions are sequential; each person looks at the decisions made by previous individuals over time, before making his/her decision. This is rational behavior on the supposition that previous individuals had information the potential evaders do not. The outcome is a private decision rule, which may give rise to herd behavior. Individuals discount private information and decide to tax evade, 
emulating other individuals' actions.

Approximately one-third of U.S. households underpaid their 1998 taxes (Andreoni, Erard and Feinstein (1998) citing the 1988 taxpayer Compliance Measurement Program). Compliance and enforcement data are difficult to obtain. Studies in Spain (de Juan, Lasheras and Mayo, 1994), Switzerland (Pommerehne, Hart and Frey, 1994) and Jamaica (Alm, 1991), indicate that the effects of income, tax rates, and enforcement on compliance vary. Swiss evasion is estimated to be about $17.5 \%$ of income while in Jamaica the estimate is $3 \%$. In Jamaica $66 \%$ of taxpayers were found to have underpaid their taxes. Ineffective tax administration is a chronic problem in many developing countries and has a direct effect on tax evasion (Stella, 1993). ${ }^{1}$ Krugman, Alm, Collins and Remolina (1992) cite a study on the Philippines, which suggests that as little as 50\% of income in 1985 was actually reported and only $27 \%$ of those with taxable incomes filed. Fajnzylber, Lederman and Loayza (2002) show that income inequality raises crime rates against both individuals and the government. Flatters and MacLeod (1995) show that administrative corruption, whereby taxpayers and collectors collude to reduce remissions, is central to tax evasion in developing countries. For Argentina, Brazil and Chile, Fishlow and Friedman (1994) show tax compliance declines when current incomes decline. Therefore, the struggle to evade taxes is a struggle against government, an institution which is prone to greater weakness in poorer developing countries. These issues gain importance as large-scale tax evasions impede the ability of such countries to catch up with more developed countries. State authority is weakened, limiting its capability to play a positive role in development.

We try to understand the phenomena in which a large proportion of the population evades taxes. ${ }^{2}$ We assume individuals do not know the real value of the detection probability. Decisions are made sequentially. Each individual has private information. However, over time, individuals learn by looking at a specific sample of people, some of whom evade taxes and some who don't, some who are caught and fined and some who are not. Of course, this may not be a random or a representative sample. Moreover, private information is only in the possession of individuals; the government does not have this information and the information each person receives may overlap with the information others receive. ${ }^{3}$ Some see the same individuals and some see others. Given 
this information, individuals update their expectations regarding the true value of the probability of detection and decide whether to evade tax obligations or fully comply.

\section{The Model}

\subsection{The basic model}

Consider a country with a large population. The population is heterogeneous with respect to the utility extracted at a given level of income. ${ }^{4}$ Denote by $U_{i}(w)$ the utility level of individual $i$ with a net income level of $w$. Each individual has to determine whether to evade paying taxes. We employ the standard Yitzhaki (1974) analysis of the extent of evasion. The utility of individual $i$, with gross income $y$, a tax rate of $t$, and who chooses not to evade paying taxes, is given by

$$
U_{i}(w)=U_{i}(y(1-t)) .
$$

The expected utility of an individual who decides to evade paying taxes is given by ${ }^{5}$

$$
E\left(U_{i}(w)\right)=(1-p) U_{i}(y)+p U_{i}(y(1-F t)),
$$

where $p$ is the probability of detection, i.e., tax evaders are not left alone, but there is less than $100 \%$ auditing. If the individual is caught he will pay a fine of $F$ for each dollar of taxes that he did not pay. Thus the fine equals $y F t$.

Each individual has to decide whether to evade or not. An individual will tax evade if $\left(E\left(U_{i}(w)\right)>U_{i}(w)\right)$. From (1) and (2) we obtain that an individual will tax evade if

$$
p<\frac{U_{i}(y)-U_{i}(y(1-t))}{U_{i}(y)-U_{i}(y(1-F t))} .
$$

From standard results on risk evasion, and, as can be shown in the above equation, as the level of risk evasion increases the critical probability of detection decrease. Consider a simple example where an individual's utility is a linear function of his income: $U_{i}(w)=w$. Comparing (1) and (2) we see that for an individual to tax evade it must hold that $(1-p) y+p(1-F t) y>y(1-t)$. Therefore, the individual evades taxes if and only if $p<1 / F$.

In this section our analysis described the behavior of the individuals in the economy. The probability of detection is a given and is constant over time. Next we discuss a simple dynamic sequential model in which the detection probability is unknown. All 
individuals evaluate this probability, given the different information they may have at the time they make their decisions.

\subsection{A signaling model with homogeneous agents}

Consider the case of preferences are homogeneous, i.e. $U_{i}(w)=U(w) \forall i$, and the probability of detection is unknown. If an individual does not receive any information, his/her prior estimate regarding the probability of detection is given by $\phi$. With complete uncertainty - where the individual has no knowledge at all regarding the detection probability $-\phi$ is one-half. However, even though there is some evidence that individuals do overestimate the probability of detection, such a high estimate for a taxpayer, whose evasion has not been previously detected, is unrealistic. ${ }^{6}$ Without other information, an individual should not evade taxes. Therefore, $\phi<0.5$.

Each individual calculates the critical probability $p^{*}$ under which he will not evade paying taxes - the probability under which condition (3) does not hold. From the flow of imperfect information, a person receives a signal suggesting whether he/she should tax evade or not. ${ }^{7}$ With probability $q$ the signal providing this information is true. If false, it does not provide information regarding the true signal. To simplify we assume $q>0.5 .^{8}$ Moreover, we assume that $1-p^{*}<q$ and similarly $1-\phi<q{ }^{9}$

Individuals make sequential evading decisions. Information is periodically revalued and replenished, and may, for example, be derived from years of observing others (friends, relatives, etc.). Information is private, as the individual observes a sample of people and not the whole population. Each individual believes that his sample is representative and acts accordingly. Let us describe it in the following way: at a given age, people contemplate the possibility of evading tax payments. In the sequential decision process, people of different ages make decisions at different times. Each person has private information when making his or her decision. He or she may have received a signal, and can also observe the behavior of those preceding them. Potential tax evaders cannot, however, observe the information revealed by the signal, which was the basis for previous individuals' decisions. Given the information available, each person chooses whether to evade paying taxes or not. 
To simplify our analysis, we assume that a potential tax evader will decide to tax evade if the probability of detection is lower than the probability of not been detected, namely lower than a half. This could be generalized taking into account type I and II errors (evading when you shouldn't and not evading when you should). Here we simplify describe the mechanism where many people evade. In the appendix we describe the more generalized decision-making taking into account these two types of errors.

Assumptions governing individuals' actions. The structure of the game and Bayesian rationality are common knowledge. Moreover, we assume a person who is indifferent about following his or her own signal and emulating someone else's choice will follow his or her own signal (assumption a). We now consider the different possibilities facing the individual in the sequential decision process.

First person making a decision. This person will follow his or her signal. The probability that this action is maximizing the individual's utility is $q>0.5$.

Second person. If this person has received a signal not to evade and the previous person has decided not to evade taxes then he or she follows the first person. If the two persons have different signals, the second person is indifferent about following his or her own signal or emulating the other person. This is true as both persons have the same probability of their signal being true (q). Using assumption $a$, the second person will thus follow his or her own signal.

Third person. Denote the action of evading by " $a$ " and the decision not to evade by " $n$ ". If the first two persons have chosen to evade, and person number three has a signal not to evade, then the probability that the third person should evade is given by $\operatorname{Pr}(a \mid a, a, n)$ (the sequence “ $a, a, n$ ” states the first person evaded, the second person evaded and the their person received a signal not to evade). In this case the third person will decide to evade. ${ }^{10}$ Formally, using the Bayesian rule:

$$
\operatorname{Pr}(a \mid a, a, n)=\frac{\operatorname{Pr}(a, a, n \mid a) \operatorname{Pr}(a)}{\operatorname{Pr}(n, n, a)}=\frac{q^{2}(1-q)(1-\phi)}{q^{2}(1-q) \phi+q(1-q)^{2}(1-\phi)} .
$$

For example, if $q=0.55$ and $\phi=0.48$ then we obtain $\operatorname{Pr}(a \mid a, a, n)=0.6735$. An individual will evade if, and only if, the probability to evade is greater than a half. In other words, the probability of not being caught, $\operatorname{Pr}(a \mid a, a, n)$, is greater than the probability of being 
caught, $\operatorname{Pr}(n \mid a, a, n)$. In the same way, the person can calculate the probability not to evade:

$$
\operatorname{Pr}(n \mid a, a, n)=\frac{\operatorname{Pr}(a, a, n \mid n) \operatorname{Pr}(n)}{\operatorname{Pr}(n, n, a)}=\frac{q(1-q)^{2} \phi}{q^{2}(1-q)(1-\phi)+q(1-q)^{2} \phi} .
$$

For $q=0.55$ and $\phi=0.48, \operatorname{Pr}(n \mid a, a, n)=0.3265$.

Since $\phi<0.5$ and $q>0.5$ the ratio of both probabilities is given by:

$$
\frac{\operatorname{Pr}(a \mid a, a, n)}{\operatorname{Pr}(n \mid a, a, n)}=\frac{q(1-\phi)}{(1-q) \phi}>1
$$

According to our example, $\frac{\operatorname{Pr}(a \mid a, a, n)}{\operatorname{Pr}(n \mid a, a, n)}=1.324 .{ }^{11}$

Proposition 1: Given the above assumptions, in a population consisting of $k$ tax evading individuals and $d$ individuals who received signals not to evade, all new individual deciding whether to evade or not, will choose, regardless of their signal, to evade taxes if $k-d \geq 2$.

Proof: Given a population consisting of $k$ tax evading individuals and $d$ individuals who received signals not to evade and do not evade, a new individual, who receives a signal not to evade, will calculate the probability of not being caught:

$$
\operatorname{Pr}\left(a \mid a \ldots a_{k}, n \ldots n_{d}, n\right)=\frac{q^{k}(1-q)^{d+1}(1-\phi)}{\operatorname{Pr}\left(a \ldots a_{k}, n \ldots n_{d}, n\right)} .
$$

In this case, with probability $q^{k}, k$ individuals receive the correct signal and with probability $(1-q)^{d+1}, d$ individuals receive the wrong signal. In the same way the individual may calculate the probability of being caught:

$$
\operatorname{Pr}\left(n \mid a_{\ldots} . a_{k}, n \ldots n_{d}, n\right)=\frac{q^{d+1}(1-q)^{k} \phi}{\operatorname{Pr}\left(a \ldots a_{k}, n \ldots n_{d}, n\right)} .
$$

Thus, we may look at the ratio of the two probabilities:

$$
\frac{\operatorname{Pr}\left(a \mid a_{\ldots} . . a_{k}, n \ldots n_{d}, n\right)}{\operatorname{Pr}\left(n \mid a \ldots a_{k}, n \ldots n_{d}, n\right)}=\frac{q^{k}(1-q)^{d+1}}{q^{d+1}(1-q)^{k}} \frac{(1-\phi)}{\phi}=\left(\frac{q}{1-q}\right)^{k-d-1} \frac{(1-\phi)}{\phi} .
$$


Thus for equations (4), (5) and (6), ratio (9) is greater than one if $k-d-1 \geq 1$, i.e., $k-d \geq 2$.

The proposition states that if the number of tax evaders is greater than the number of individuals who do not evade taxes by at least two, then each new individual, who has to decide whether to evade or not, will always decide to evade regardless of what type of signal he or she receives. Individuals hear about those in their sample who evaded. Moreover, even though there may be overlapping among the samples, each individual has his own reference group - the large group of people with whom an individual interacts and his information is private. One could think that the reference group facing each individual is from a specific profession. We may see all doctors evading while lawyers do not. Or we may witness the doctor visiting his lawyer friend while the plumber is working in the house; the doctor obtains information about the actions of the lawyer and the plumber. Here there is overlapping between different reference groups and thus the evasion decision is interdependent among groups. ${ }^{12}$

\subsection{A signaling model with apprehension}

We now consider the case in which individuals not only observe the actions of others but also observe if any of the tax evaders were detected by the authorities. Case-Based Decision Theory (Gilboa and Schmeidler, 1995) states that if an individual sees that someone has been apprehended it may have a stronger impact on the individual's perception.

Let us look at the case in which an individual makes a decision on whether to evade taxes. The information he/she is faced with at the time of the decision is: 1) there are $d$ non-tax evaders; 2) $k$ tax evaders and 3) from the $k$ evaders $c$ have been caught. All this information helps the individual calculate the probability, $p$, of being caught if evading.

When an individual sees someone being apprehended for evasion, this is interpreted by him/her as a probability of $g$ that he (the individual who is currently making the decision) should evade. It is not clear whether $g$ is greater or smaller than $q$ (the probability that the general signal the individual receives is true). Case based theory suggests that $g>q$, however this may not be the case. Since actually seeing someone being apprehended 
may have a stronger effect on the decision making of the individual, we distinguish between the general signals the individual receives and the number he has personally witnessed being caught evading.

If this individual receives a signal not to evade, then the probability of being caught equals:

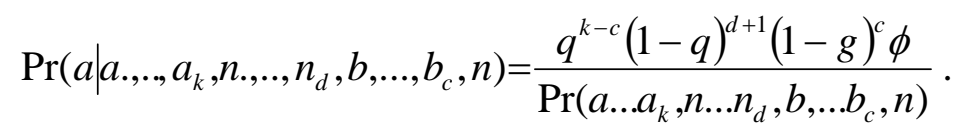

The numerator represents the case where with probability $q^{k-c}, k-c$ obtained correct signals, with probability $(1-q)^{d+1}, d+1$ individuals obtained incorrect signals and with probability $(1-g)^{c}, c$ were apprehended. Similarly, $1-\operatorname{Pr}\left(a \mid a_{\text {..,... }}, a_{k}, n ., . ., n_{d}, b, \ldots, b_{c}, n\right)$ equals

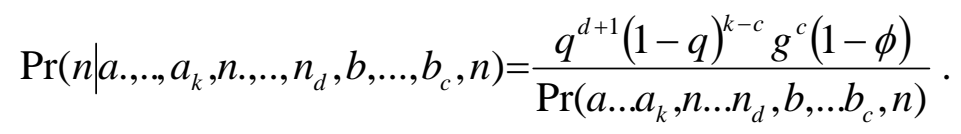

We may calculate the ratio between the two probabilities:

$$
\frac{\operatorname{Pr}\left(a \mid a ., . ., a_{k}, n ., . ., n_{d}, b, \ldots, b_{c}, n\right)}{\operatorname{Pr}\left(n \mid a ., . ., a_{k}, n ., . ., n_{d}, b, \ldots, b_{c}, n\right)}=\left(\frac{q}{1-q}\right)^{k-c-d-1}\left(\frac{1-g}{g}\right)^{c}\left(\frac{1-\phi}{\phi}\right) .
$$

When this ratio is greater than one then the "new" individual will decide to evade. Since $\left(\frac{1-\phi}{\phi}\right)>1$, the individual will decide to tax evade and go against his signal if:

$$
\frac{\ln (g / 1-g)}{\ln (q / 1-q)}<\frac{k-c-d-1}{c} .
$$

If $q=g$ it is as if the number of individuals that have decided not to evade taxes has increased by $c$, while the number of tax evaders has decreased by $c$. This shows that seeing someone being apprehended does not have a special effect on the individual deciding to evade or not. Otherwise, if $q<g$, then the difference between the number of tax evaders and non-evaders, which causes an individual to go against his/her signal, will increase. Let us illustrate this result using the numerical example presented above: $q=0.55, g=0.7, d=5$ and $c=2$; in order for an individual to go against the signal he received and decide to evade, the number of tax evaders must be at least $k=17$ and $k-c$ 
$=15$. For $g=0.8, k-c=20$. On the other hand, if $g=0.6$ then $k-c=12$. We may thus conclude that:

Proposition 2: If individuals observe others caught evading taxes and $g>q$, in order for individuals to go against their own signal and evade: (a) The difference, between the number of individuals who evade taxes and those who do not evade, will be larger than in the case where detection is not observed; (b) Increasing the probability that the signal, generated by observing detection is true, will require an increase in the difference between the numbers of individuals who evade and those who do not tax evade.

\subsection{A signaling model with heterogeneous agents}

We return to the basic description of the model in which the individuals are heterogeneous with respect to the levels of utility generated from a given income; this can be thought of as different levels of risk aversion. Let $U_{i}(w)$ denote the utility level of individual $i$ with income level of $w$.

Individuals now differ with respect to their risk aversion and, as we have a continuum of individuals distributed by level of utility for a given detection probability, there will be a proportion of the population that will evade. This can be seen from equation (3):

$$
(1-p) U_{i}(y)+p U_{i}(y(1-F t))>U_{i}(y(1-t)) .
$$

For a given gross income level of $y$, each individual will have a different critical probability, which will determine if he or she will decide to evade, $p_{i}{ }^{*}$. It is important to note that all individuals are different in their degree of risk aversion and thus have a different critical probability for evasion. Individuals may know the distribution of risk aversion in the population; however, they do not know the actual risk aversion level of each individual. Therefore, the value of $q_{i}$, the probability that the signal is true, depends on the risk aversion of the individual who is receiving the signal. The same would be true for the value of $g_{i}$. An individual receiving a signal does not have knowledge of the level of risk aversion for each person in the population, therefore he calculates the weighted level of $q_{i}$ and $g_{i}$ for all those that received a signal or have been apprehended given the distribution of risk aversion in the population. In other words, if the distribution of risk aversion in the population of the reference group of an individual is given by $f($.) 
(level of risk aversion is given by $\lambda$ ), then the individual, who has to decide to tax evade or not, will take into account all the information available and calculate a probability $q$ and $g: q=\theta(\underline{q}, f()$.$) and g=\omega(\underline{g}, f()$.$) where \underline{q}$ and $\underline{g}$ are information vectors and $\theta($. and $g=\omega($.) are functions that transfer the information into a one dimension variable. For example the functions can be the means of the distribution: $q=\int q_{\lambda} f(\lambda) d \lambda$ and $g=\int g_{\lambda} f(\lambda) d \lambda$. With $q$ and $g$, each individual calculates the detection probability.

First period. Assume that in the model's first period all individuals receive signals. All individuals for whom the probability of detection is lower than the probability that the signal is true, $q$, decide to evade. Others join those who did not receive a signal and do not evade.

Second period. In the second period, all individuals who did not evade receive signals. ${ }^{13}$ They either receive a signal to evade or a signal not to evade. As in the first period, the probability that the signal is true is $q$. Moreover, individuals receiving signals in the second period observe the actions of the individuals from the first period. They can see how many individuals decided in the previous period to evade and how many of them were detected by the authorities.

Using a variation in the notation presented above: at time $t$ each individual knows that during the previous period, $t-1$, there were $d_{t-1}$, non-tax evaders, $k_{t-1}$ tax evaders and from the $k_{t-1}$ evaders $c_{t-1}$ have been caught. Thus an individual who received a signal not to evade may calculate the ratio between the probability of evading and not evading in a similar way to (7):

$$
\frac{\operatorname{Pr}\left(a \mid a_{., . .,}, a_{k_{t-1}}, n_{., . .,}, n_{d_{t-1}}, b, \ldots, b_{c_{t-1}}, n_{t}\right)}{\operatorname{Pr}\left(n \mid a_{1}, . ., a_{k_{t-1}}, n ., . ., n_{d_{t-1}}, b, \ldots, b_{c_{t-1}}, n_{t}\right)}=\left(\frac{q}{1-q}\right)^{k_{t-1}-c_{t-1}-d_{t-1}-1}\left(\frac{1-g}{g}\right)^{c_{t-1}}\left(\frac{1-\phi}{\phi}\right) .
$$

Remember that $\phi<0.5$, thus, $\left(\frac{1-\phi}{\phi}\right)>1$. In the previous section, the criterion for tax evasion was that this ratio is greater than one. In the current story, the higher the value of this ratio, the larger is the number of individuals who evade taxes. It is clear that if the total number of evaders who are not caught increases over time against a given amount of 
evaders who have been caught, the ratio increases and the number of evaders increases from period to period. Moreover, in each period, the increase in tax evaders increases the ratio for those considering tax evasion in the next period. In the case where the number of tax evaders who have been caught increases, whether or not an individual will evade is not clear. Note this individual receives a signal not to evade therefore evasion is going against the signal he obtained. This will happen only if the increase in tax evaders is relatively greater than the number of evaders who have been detected.

Assume that equation (13) is true at time $t-1$. At time $t$ the question is: what happens at the boundary (right hand side of equation (13))? This, of course, depends on the increase in the total number of evaders, non-evaders and number of individuals who have been caught over time. Denote the total number of evaders, tax payers and the total of those caught evading as follows: $k=\sum_{t=0}^{T} k_{t}, d=\sum_{t=0}^{T} d_{t}$ and $c=\sum_{t=0}^{T} c_{t}$. The values of $q$ and $g$ are known to all the individuals. We are concerned with the right hand side of equation number (13).

$$
Q=\frac{k-c-d-1}{c} .
$$

We consider how an increase in the number of individuals, who have been caught, affects the boundary determining the number of individuals evading tax payments, $Q$. Of course, when we move from one period to another, the number of individuals, who are caught may increase but, at the same time, the total number of individuals deciding to evade paying taxes and the number of individuals paying taxes who received signals, may increase. The change in $Q$, as a result of an increase in the number of individuals caught, is given by

$$
\frac{\partial Q}{\partial c}=\frac{c\left(\frac{\partial k}{\partial c}-1-\frac{\partial d}{\partial c}\right)-(k-c-d-1)}{c^{2}}=\frac{k\left(\varepsilon_{k}-1\right)+1+d\left(1-\varepsilon_{d}\right)}{c^{2}},
$$

while $\varepsilon_{k}=\frac{\partial k / k}{\partial c / c}$ and $\varepsilon_{d}=\frac{\partial d / d}{\partial c / c}$.

From (16) we can see the conditions under which an increase in the total number of all three components increases this boundary. A sufficient condition for the boundary to increase is that the proportion of individuals being caught is less than the proportion of 
increase in the number of individuals deciding to evade tax payments and is greater than the increase in those who decide not to evade. Summarizing,

Proposition 3: Given an increase in the number of evaders, non-evaders and individuals caught evading, there exist conditions under which new individuals will decide to tax evade, regardless of the signal: $k\left(\varepsilon_{k}-1\right)+d\left(1-\varepsilon_{d}\right)>-1$, i.e., the increase in the number of individuals caught is relatively smaller than the increase in the other components.

\section{Concluding remarks}

We try to understand the phenomena in which a large proportion of the population evades taxes. The struggle to evade taxes is a struggle against government, a man-made institution, which is prone to greater weakness in poorer developing countries. These issues gain importance as large-scale tax evasion increasingly impedes the ability of such countries to catch up with more developed countries. Moreover, the authority of the state is weakened, limiting its capability to play a positive role in development. The theory of information cascades has been usefully applied to explaining behavior in a number of different contexts where individuals appear to discount their private information and to copy the decisions of others. Such duplication, based on what others are doing, reinforces the tendency for further duplication.

Weak states are a characteristic of poor developing economies. While corruption exists in rich and poor countries, in rich countries the average person can go through their daily activities without directly confronting corruption while in poor countries corruption is more direct, more in your face and more widespread. Some interpret the widespread corruption in developing countries as part of their moral (or amoral) fabric. We like to think this is not so, that there is generally not a cultural acceptance of corruption; what we witness is people behaving under severe information constraints. We presented a model that uses different elements from the theory of information cascades and show conditions under which individuals decide to emulate other individuals and evade. The probability of detection is unknown. Individuals considering the option of evading taxes seek as much information as possible before making a decision. This can bring about a 
situation in which any potential tax evader will, in the end, evade as he sees others doing, so believing they have information which he does not have. In the long run, the tax evasion may include the entire population. 


\section{References}

Alm, James, "A Perspective on the Experimental Analysis of Taxpayer Reporting," Accounting Review 66(3) (1991): 577-93.

Akerlof, George A., "A Theory of Social Custom of Which Unemployment May Be One Consequence," Quarterly Journal of Economics 94(4) (1980): 749-75.

Allingham, Michael G. and Agnar Sandmo, "Income Tax Evasion: A Theoretical Analysis," Journal of Public Economics 1(3-4) (1972): 323-38.

Andreoni James B., Brian Erard and Jonathan Feinstein, "Tax Compliance," Journal of Economic Literature 36(2) (1998): 818-60.

Banerjee, Abhijit V., "A Simple Model of Herd Behavior," Quarterly Journal of Economics 107(3) (1992): 797-817.

Bose, Gautam and Shubhashis Gangopadhyay, "Intermediation in Corruption Markets," Indian Growth and Development Review, forthcoming.

Das-Gupta, Arindam and Dilip Mookherjee. Incentives and Institutional Reform in Tax Enforcement: An Analysis of Developing Country Experience, New Delhi: Oxford University Press, 1998.

Das-Gupta, Arindam and Ira N. Gang, "Decomposing Revenue Effects of Tax Evasion and Tax Structure Changes," International Tax and Public Finance 7(2) (2000): 177-94.

Das-Gupta, Arindam, Radhika Lahiri and Dilip Mookherjee, "Income Tax Compliance in India: An Empirical Analysis," World Development 23(12) (1995): 2051-64.

de Juan, Ana, Miguel A. Lasheras and Rafaela Mayo, "Voluntary Tax Compliant Behavior of Spanish Income Tax Payers," Public Finance 49(0) (1994): 90-105.

Dunn, David, "Tax Compliance with Untaxed Fringe Benefits: Evidence from Mexico," IMF Discussion paper Washington DC (1992).

Epstein, Gil S, "Informational Cascades and the Decision to Migrate," IZA Working Paper (2002).

Fajnzylber, Pablo, Daniel Lederman, and Norman Loayza, "What Causes Violent Crime?" European Economic Review 46(7) (2002): 1323-57.

Fishlow, Albert and Jorge Friedman, "Tax Evasion, Inflation and Stabilization," Journal of Development Economics 43(1) (1994): 105-23.

Flatters, Frank and W. Bentley MacLeod, "Administrative Corruption and Taxation," International Tax and Public Finance 2(3) (1995): 397-417.

Gang, Ira N. and Arindam Das-Gupta, "Value Added Tax Evasion, Auditing and Transactions Matching," in McLaren, John. "Institutional Elements of Tax Design and Reform," Washington, D.C.: World Bank (2003): 25-48.

Geeroms, Hans and Hendrik Wilmost, "An Empirical Model of Tax Evasion and Tax Avoidance," Public Finance 40(2) (1985): 190-209. 
Gilboa, Itzhak and David Schmeidler, "Case-Based Decision Theory," Quarterly Journal of Economics 110(3) (1995): 605-39.

Goswami, Omkar, Amal Sanyal, and Ira N. Gang, "Taxes, Corruption, and Bribes: A Model of Indian Public Finance," in Roemer, Michael and Jones, Christine. Markets in Developing Countries: Parallel, Fragmented, and Black. San Francisco, California: Institute for Contemporary Studies Press (1991): 209-220.

Gul, Faruk and Russell Lundholm, "Endogenous Timing and the Clustering of Agents' Decisions,” Journal of Political Economy 103(5) (1995): 1039-66

Hunt, Jennifer, "Trust and Bribery: The Role of the Quid Pro Quo and the Link with Crime," NBER Working Paper 10510 (2004).

Johnston, David Cay. "Rate of All I.R.S Audits Falls; Poor Face Intense Scrutiny," The New York Times, New York (2001).

Krugman, Paul R., James Alm, Susan. M. Collins and Eli M. Remolina, Transfroming the Philippine Economy, Quezon City: AOP Production Unit, Inc. (1992).

Myles, Gareth D. and Robin A. Naylor, "A Model of Tax Evasion with Group Conformity and Social Customs," European Journal of Political Economy 12(1) (1996): 49-66.

Pommerehne, Werner W., Albert Hart and Bruno S. Frey, "Tax Morale, Tax Evasion and the Choice of Policy Instruments in Different Political Systems," Public Finance 49(0) (1994): 52-69.

Sanyal, Amal, Ira N. Gang and Omkar Goswami, "Corruption, Tax Evasion and the Laffer Curve," Public Choice 105(1-2) (2000): 61-78.

Scharfstein, David S. and Jeremy C. Stein, "Herd Behavior and Investment," American Economic Review 80(3) (1990): 465-79.

Stella, Peter, "Tax Farming: A Radical Solution for Developing Country Tax Problems?" International Monetary Fund Staff Papers 40(1) (1993): 217-25.

Yitzhaki, Shlomo, "Income Tax Evasion: A Theoretical Analysis," Journal of Public Economics 1(3-4) (1974): 201-02. 


\section{Endnotes}

1. Weak tax administration plagues countries such as India, Mexico and different CIAT countries (Dunn, 1992; Das-Gupta, Lahiri and Mookherjee, 1995; Das-Gupta and Mookherjee, 1998). Das-Gupta and Mookherjee, 1998, consider policies governments undertake to enhance their capability of enforcing essential taxes, focusing on the level of tax evasion.

2. Alternatively, one could consider where a large proportion of the population does not evade.

3. David Cay Johnston (New York Times, 16 February 2001) presented data on the percentage of individuals audited in 1999, 2000 and a forecast for 2001. The article also contains information on the correlation between being audited and income level. The Economic Times (www.economictimes.com) has published many articles on tax evasion in India and other developing countries: December 13, 2004, the Income Tax department demanded Rs 820 crore (one crore $=10$ million) from Slocum Investment; an October 28 editorial states "a large part of tax evasion and cheating of investors by managements can also be traced back to the absence of a transparent system of political funding."

4. People may have different social customs and conformity costs for evading taxes (Myles and Naylor, 1996, Akerlof, 1980).

5. In Yitzhaki (1974) the question addressed is to what extent to evade taxes.

6. Audit rates and detection probabilities typically differ among taxpayers even in explicitly specified groups. Only $4.1 \%$ of all U.S. taxpayers whose federal returns were reassessed following an audit received any penalty for fraud, negligence, false withholding, failure to report tips, or other infractions (Andreoni, Erard and Feinstein, 1998).

7. A different way of looking at this is that an individual receives information which tells him whether the real probability is less or greater than $p^{*}$. This can be generalized to the individual receiving a signal with probability $0<l<1$. The main results still hold. This is saying the signal received is whether the detection actual probability is greater or less than the critical one.

8. If the probability of $q$ is not certain, the individual chooses to evade taxes using mixed strategies. As more information arrives having positive signals with regard to tax evasion, even though the individual acts according to mixed strategies, the probability of tax evasion increases.

9. This simplifies matters. An equivalent assumption is $1-p-s<q$ for $s>0$ and similarly for $\phi$.

10. Of course, this is true when the first two individuals choose not to evade paying taxes and the third receives a signal to evade. The last will emulate the previous individual's actions. 
11. If one of the previous persons chooses not to evade and the other person chooses to evade, then the third person will follow his signal,

$$
\operatorname{Pr}(a \mid n, a, n)=\frac{\operatorname{Pr}(n, a, n \mid a) \operatorname{Pr}(a)}{\operatorname{Pr}(n, a, n)}=\frac{q(1-q)^{2}(1-\phi)}{q^{2}(1-q) \phi+q(1-q)^{2}(1-\phi)} \text {. Note } \frac{\operatorname{Pr}(n \mid n, a, n)}{\operatorname{Pr}(a \mid n, a, n)}=\frac{q}{1-q} \frac{\phi}{1-\phi} \text {. It }
$$

is clear that if $\phi=0.5$ (if an individual does not receive any information then his/her prior estimate regarding the probability of detection is one half), the third individual follows his signal and not evade. Given our assumption that $1-\phi<q$, it is clear the ratio in (7) is greater than one and thus the individual will follow his signal and not evade.

12. Herd behavior may also cause a large decrease in the proportion of evaders. Each knows with probability $p$ that people receive signals; if he feels he knows a sufficiently large proportion do not evade (a proportion greater than $p$ ), it would be clear to him that some received signals not to evade. He can use this information to decide whether to evade. If the proportion not evading is sufficiently large, then, even if he receives information to evade, he will not.

13. This can be generalized to the case where all individuals receive signals, i.e., not only the individuals who did not evade taxes. This does not change the results. 


\section{Appendix - type one and typo two errors}

When deciding whether to evade, each individual examines two types of errors: I. Evade when he/she shouldn't; II. Not evade when he/she should. Define: (i) $U$ as individual's utility from not evading, (ii) $E(z)$ as expected utility from evading given the value of the detection probability, $p$, equals $z$ and (iii) $V\left(p_{0}\right)$ as expected gain if choosing evasion optimally for $p=p_{0}$ when actually $p=\lambda$. The expected gain from ignoring the signal compared to following it for $p_{0}<p^{*}<\lambda$ is $G()=.(1-q)\left[E\left(p_{0}\right)-U\right]-q\left[U-V\left(p_{0}\right)\right]$. The value of $G\left(p_{0}, q, \lambda\right)$ may be positive or negative depending on the precise values of $p_{0}, q$, the distribution of $\lambda$ and the degree of risk aversion of the individuals. Consider how $G\left(p_{0}, q, \lambda\right)$ is calculated. The first part is straight-forward. The second part, $V\left(p_{0}\right)$, needs more explanation. Given the signal and the information an individual has, he recalculates the probability of detection $p$. He then comes up with updated probability, the value of $p_{0}$. However, this may not be the correct value and the probability of detection may be higher. Thus real expected utility may be lower than the individual believes. Expected utility depends on the normalized distribution of alternative probabilities given the individual's information, $f(\lambda)$. Using (2), $V\left(p_{0}\right)=\int_{\lambda>p_{0}}(1-\lambda) U_{i}(y) f(\lambda) d \lambda+\int_{\lambda>p_{0}} \lambda U_{i}(y(1-F t)) f(\lambda) d \lambda$. Every time the individual updates the probability of detection and it decreases, the distribution $f(\lambda)$ puts a higher density on the lower levels $\lambda$ and a lower density of the higher levels of $\lambda$. The rule the individual will follow is therefore: $G\left(p_{0}, q, \lambda\right)\left\{\begin{array}{ll}<0 & \text { evade } \\ =0 & \text { Indifferent } \\ >0 & \text { do not evade }\end{array}\right.$. Notice that in calculating $G($.$) the individual calculates the updated probability of detection p_{0}$ given all the information he has at the time. The individual can calculate the critical probability under which he will decide whether to evade or not. The critical probability will be a function of the individual's utility function, the probability that the signal is true, $q$, the distribution of $\lambda$. Denote this critical probability by $g\left(I_{0}, q, \lambda\right)$. Thus rule becomes: $p_{0}\left\{\begin{array}{l}<g(q, \lambda) \text { evade } \\ =g(q, \lambda) \text { Indifferent } \\ >g(q, \lambda) \text { donotevade }\end{array}\right.$ If the probability of not been detected 1-p is greater than 
$1-g(q, \lambda)$ then the individual will tax evade. Therefore, there is no closed-form solution. To obtain a closed-form analysis, and since we are talking about two types of decisions, we assume if the first individual obtains a signal, the critical probability of not been detected, $1-g(q, \lambda)$ equals a half. If more information is obtained in favor of evasion, this critical probability will decrease. Therefore, a sufficient condition to evade will be higher than half with the probability of not being caught, given all the information available. This is identical to an individual, who calculates the probability that the correct action is tax evasion, and, if this is greater than the probability of not evading, he will decide to tax evade (similar to the herd behavior literature; Banerjee, 1992, Scharfstein and Stein, 1990). 